\title{
STRATEGI DIVERSIFIKASI PRODUK WISATA UNTUK MENARIK MINAT KUNJUNGAN WISATAWAN DI DESA CELUK, KABUPATEN GIANYAR
}

Zilvany Destin ${ }^{\mathrm{a}, 1}$, Nararya Narottama ${ }^{\mathrm{a}, 2}$

${ }^{1}$ zilvanydestin@gmail.com, ${ }^{2}$ nararya.narottama@unud.ac.id

a Program Studi S1 Destinasi Pariwisata, Fakultas Pariwisata, Universitas Udayana, JL, Dr.R, Goris, Denpasar, Bali 80232 indonesia

\begin{abstract}
Celuk Village located in Sukawati, Gianyar, Bali. This village has natural and cultural potencies which can be developed into tourism attractions. For many decades, Celuk is internationally recognized for its silver crafts industries. Unfortunately, since 1998 the tourist visits to this village has been declined, mostly caused by many new competitors in the business. For this reason, this research aims to develop a new strategy to maximize Celuk's tourism potentials and increase tourists visit.

The research approach is qualitative descriptive, the methods such as field observation, in-depth interview with 5 key informants and literature studies. The data analysis using SWOT technique. This research is proposed short-term, mid-term and long-term strategy. Then, based on the result, the best approach is diversification and involvement of local community into all tourism activities. Hopefully, this can make tourism activities in Celuk more diverse and attracts more tourists to come.
\end{abstract}

Keyword: Diversification, products, tourism.

\section{PENDAHULUAN}

Banyak negara sejak beberapa tahun terakhir menggarap pariwisata dengan serius dan menjadikan pariwisata sebagai sektor unggulan dalam perolehan devisa, penciptaan lapangan kerja maupun pengentasan kemiskinan. Pentingnya peranan pariwisata dalam pembangunan ekonomi di berbagai negara sudah tidak diragukan lagi (Pitana, 2002).

Pencetus tourism research Angelo Maroti (1923) asal Italia sudah sejak lama mengenalkan kajian ekonomi pariwisata secara makro dan mikro. Begitupula R. Gluckman (1935) dari Jerman mencetuskan tourism theory. Ekonomi menjadi landasan penting karena dampaknya dirasakan cepat dan memberikan manfaat bagi suatu negara (Anom, dkk., 2020).

Pembangunan daerah yang mengandalkan sektor pariwisata dan telah terbukti mampu bersaing secara ekonomi di Indonesia adalah Bali. Bali sebagai tujuan wisata dunia memiliki berbagai potensi yang menunjang pertumbuhan kepariwisataan (Hariyana, dkk., 2015). Tetapi perkembangan pariwisata Bali tidak sesederhana dan semudah yang terlihat. terdapat proses yang berliku dan jatuh bangun dalam perjalanan pariwisata Bali (Mahagangga, 2016).

Seperti Desa Celuk, kecamatan Sukawati, Kabupaten Gianyar memiliki potensi alam yang dapat dimanfaatkan untuk pariwisata seperti sungai, sawah. Sejak krisis moneter tahun 1998, kunjungan wisatawan ke Desa Celuk mengalami penurunan. Selain itu Desa Celuk juga merasakan dampak dari peristiwa bom Bali pada tahun 2002 dan erupsi Gunung Agung pada tahun 2017 yang mengakibatkan semakin menurunnya angka kunjungan wisatawan (hasil wawancara dengan Kepala Desa, 23 April 2019).
Dewasa ini, wisatawan yang datang membeli produk perak Celuk menurun (apakah jenuh? atau inovasi yang kurang?), sebagian lagi memesan kerajinan perak Celuk secara online. Ada juga wisatawan yang membeli kerajinan perak Celuk di artshop di luar wilayah Celuk. Hal ini membuat masyarakat di Celuk pemilik Home industry merasa dirugikan karena tidak mendapat keuntungan langsung dari wisatawan yang menjungi Desa Celuk.

Diversifikasi produk wisata bertujuan mengatasi kejenuhan wisatawan akan produk di Desa Celuk. Oleh karena itu dengan adanya penambahan produk wisata melalui penganekaragaman produk produk wisata dari potensi alam dan budaya yang potensial dan inovatif serta strategi diversifikasi yang diharapkan mampu menarik minat wisatawan untuk mengunjungi Desa Celuk.

Berdasarkan pemaparan diatas maka penelitian ini penting untuk membahas bagaimana identifikasi produk wisata di Desa Celuk, Kabupaten Gianyar dan bagaimana strategi diversifikasi produk wisata untuk menarik minat kunjungan wisatawan di Desa Celuk, Kabupaten Gianyar.

Studi mengenai pemasaran produk dan pameran/festival seni dan budaya telah lama menarik minat para peneliti. Tampak sebagian besar penelitian tentang pemasaran pada satu dekade terakhir berfokus pada strategi pemasaran digital (Wulandari, dkk., 2019). Penelitian terkait yang dilakukan oleh Parimin (2018) menghasilkan strategi diversifikasi yaitu mengemas kembali produk wisata, memasukkan atraksi baru dalam kalender wisata tahunan, memanfaatkan teknologi, desain baru dalam produk wisata. Penelitian Lustiyanti dan Kurniawati (2017), tentang pengrajin perak yang dapat mengetahui tindakan dalam strategi pelayanan dan 
produk, sehingga mampu menghadirkan pelayanan tanpa cacat kepada pelanggan, maka kepuasan pelanggan akan tercapai. Penelitian lainnya dilakukan oleh Narottama (2016) mengenai perkembangan pariwisata di kawasan Sanur, Bali dengan konsep pemasaran berbasis Tri Hita Karana memiliki banyak dampak terhadap kehidupan masyarakat baik secara sosial, ekonomi dan lingkungan.

Diversifikasi produk merupakan upaya mencari dan mengembangkan produk atau pasar yang baru atau keduanya, dalam rangka mengejar pertumbuhan, peningkatan, penjualan, profitabilitas dan fleksibilitas (Tjiptono dalam Sukmaratri dan Damayanti 2016). Diversifikasi produk wisata dimaksud tidak mengubah keaslian potensi tetapi menambah keragaman produk wisata yang telah ada untuk menghindari kejenuhan dan memperpanjang lama tinggal wisatawan (Pitana dalam Naibaho, 2011).

\section{METODE PENELITIAN}

Penelitian ini berlokasi di Desa Celuk, Kecamatan Sukawati, Kabupaten Gianyar, Bali. Ruang lingkup penelitian dalam penelitian ini meliputi identifikasi potensi berupa atraksi, akses, fasilitas, pelayanan tambahan. Strategi diversifikasi produk pariwisata berupa potensi alam dan budaya, keikutsertaan masyarakat, peran stakeholder.

Jenis data yang digunakan dalam penelitian ini yaitu, data kualitatif berupa sejarah Desa Celuk, identifikasi Desa Celuk saat ini, kelebihan dan kurangan yang dimiliki Desa Celuk. Kendala dan kesulitan dalam mengembangkan parwisata di Desa Celuk. Penelitian ini juga menggunakan data kuantitiatif sebagai data sekunder, data yang diperlukan adalah jumlah penduduk dan data jumlah pemilik home industry di Desa Celuk.

Sumber data dalam penelitian ini adalah data primer berupa kondisi saat ini Desa Celuk, kelebihan, kekurangan, kendala dan kesulitan dalam mengembangkan pariwisata di Desa Celuk. Data sekunder, berupa sejarah Desa Celuk, jumlah kunjungan wisatawan, dan jumlah pemilik home industry.

Pengumpulan data yang ada dilakukan dengan beberapa teknik. Teknik pertama yaitu observasi, data yang diperoleh adalah kondisi Desa Celuk saat ini, akses menuju Desa Celuk, kelebihan dan keunikan yang dimiliki Desa Celuk. Peneliti melakukan observasi selama dua minggu di lapangan. Teknik kedua yaitu wawancara, dilakukan pada tanggal 23 Februari, 23 April - 03 Mei 2019 untuk mendapatkan data mengenai kondisi Desa Celuk saat ini, atraksi wisata yang ada di Desa Celuk. Kendala dan kesulitan dalam pelaksanaan pariwisata di Desa Celuk. Wawancara dilakukan dengan teknik purposive sampling. Informan kunci yang dimaksud peneliti adalah kepala Desa Celuk, ketua POKDARWIS Desa
Celuk, masyarakat ataupun pelaku usaha pariwisata di Desa Celuk. Teknik ketiga studi pustaka, pengumpulan data dengan cara penelaahan catatan, literarur yang berhubungan dengan penelitian. Data yang didapatkan adalah sejarah Desa Celuk, jumlah kunjungan dan profil Desa Celuk.

Pada penelitian ini teknik analisis data yang digunakan adalah deskriptif kualitatif. Selain deskriptif kualitatif penelitian ini juga menggunakan teknik analisis SWOT untuk mencari strategi diversifikasi produk wisata. Analisis SWOT menggambarkan bagaimana peluang serta ancaman eksternal yang dihadapi untuk menyelesaikan dengan kekuatan dan kelemahan yang dimiliki.

\section{PEMBAHASAN}

\section{Gambaran Umum Lokasi Penelitian}

Desa Celuk termasuk salah satu wilayah di Kecamatan Sukawati, Kabupaten Gianyar Provinsi Bali. Desa Celuk terkenal dengan kerajinan perak yang sudah ada sejak seratus tahun yang lalu. Selain perak desa Celuk juga memiliki sumber daya alam yang juga dapat dijadikan daya tarik wisata. Masyarakat desa Celuk sudah belajar memande perak sejak tahun 1935 hingga saat ini, awalnya pengrajin perak hanya membuat perhiasan dan pernak pernik untuk pernikahan raja, kemudian berkembang hingga kini membuat berbagai anting, kalung, cincin dan aksesoris - aksesoris lainnya untuk digunakan secara umum. Oleh karena itu profesi tukang perak di Desa Celuk sangat berkembang. Perkembangan Desa Celuk sebagai penghasil kerajinan perak di Bali dan adanya wisatawan yang berkunjung membuat masyarakat di Desa Celuk beralih profesi dari petani menjadi pengrajin perak dan mendirikan artshop - artshop yang setiap tahunnya bertambah.

Krisis bom Bali yang terjadi pada tahun 2002 mempengaruhi industri kerajinan perak di Desa Celuk, penurunan tingkat kunjungan wisatawan yang drastis membuat beberapa pengusaha dan pengrajin perak di Desa Celuk tidak mampu bertahan, kemudian memilih beralih ke bisnis lain dan bahkan berhenti dari bisnis kerajinan perak. Selain faktor krisis bom Bali yang membuat merosotnya bisnis kerajinan perak di Desa Celuk adalah kalah persaingan dengan pesaing dari "luar" maupun mengusaha pengusaha yang memiliki jaringan yang lebih luas untuk pasar dan kurangnya inovasi terhadap produk wisata yang ditawarkan di Desa Celuk. Walaupun saat ini masyarakat Desa Celuk juga dalam tahap ingin membangkitkan kembali home industry kerajinan Perak Celuk dengan berbagai macam usaha.

\section{Identifikasi Produk Wisata di Desa Celuk \\ a. Attraction (Atraksi)}

Desa Celuk memiliki banyak ragam atraksi yang dapat ditawarkan kepada wisatawan, Desa 
Celuk memiliki daya tarik wisata alam dan budaya yang dapat dipadukan menjadi suatu kegiatan wisata. Berikut ini adalah daya tarik dan potensi wisata yang dimiliki Desa Celuk:

- Desa Celuk adalah pusat kerajinan perak terbesar di Bali. Wisatawan dapat melihat langsung proses pembuatan kerajinan perak di artshop di sepanjang jalan di Desa Celuk. Wisatawan juga dapat belajar bagaimana cara membuat kerajinan perak secara langsung. Pemerintah Desa Celuk juga berencana membuat museum Perak Celuk untuk mendemostrasikan dan memperlihatkan kepada wisatawan bagaimana sejarah dan berkembangan perak di Desa Celuk. Museum ini juga nantinya akan memperlihatkan perkembangan desain kerajinan perak dari waktu ke waktu.

- Desa Celuk memiliki potensi alam berupa sungai yang dapat dijadikan daya tarik wisata. Sungai Wos, nantinya akan dijadikan sarana atraksi air berupa tubing menyusuri sungai sepanjang 2kilometer, swing di sisi tebing dan jalur trekking. Namun, sungai ini masih dalam tahap pembersihan dan pembuatan akses yang layak.

- Desa Celuk juga memiliki areal persawahan dan pertanian, areal persawahan nantinya akan di kembangkan menjadi jalur trekking dan ATV di sepanjang tepi sawah namun tidak mengganggu fungsi utama areal persawahan.

- Desa Celuk memiliki jembatan peninggalan zaman Belanda yang akan dikembangkan menjadi tempat wisata foto, jembatan ini dalam tahap renovasi agar menjadi salah satu daya tarik yang diminati wisatawan.

\section{b. Access (akses)}

Akses menuju Desa Celuk sangat mudah, wisatawan dapat menggunakan beberapa moda transportasi seperti sepeda motor, mobil pribadi, kendaraan umum, dan bus. Wisatawan juga dapat mengakses informasi melalui website website travel agent yang memuat kegiatan kegiatan wisata yang dapat dilakukan di Desa Celuk. Desa Celuk dapat di akses melalui jalan Batu Bulan dan jalan bypass Prof.Dr. Ida Bagus Mantra.

c. Amenities (fasilitas)

Desa Celuk memiliki fasilitas penunjang wisata seperti bangunan artshop - artshop masyarakat yang berjejer di sepanjang jalan di Desa Celuk dengan jumlah 187 bangunan, terdapat homestay - homestay, guest house dan villa di sekitaran Desa Celuk. Desa Celuk juga memiliki restoran dan warung warung makan, rumah ibadah berupa Sembilan pura, rumah sakit umum dan sebuah SPBU.

d. Ancilliary (Pelayanan tambahan)

Desa Celuk merupakan perangkat daerah Kabupaten Gianyar yang berkedudukan di wilayah kecamatan Sukawati dan dipimpin oleh Kepala Desa yang bertanggung jawab langsung kepada Bupati melalui Camat. Pengembangan pariwisata di Desa Celuk berada dalam pengawasan Dinas Pariwisata Kabupaten Gianyar.

Tabel 1 komposisi stakeholder pariwisata di Desa Celuk, Kabupaten Gianyar

\begin{tabular}{|l|l|l|}
\hline Pemerintah & Swasta & Masyarakat \\
$\begin{array}{l}\text { DISPAR KAB. } \\
\text { Gianyar }\end{array}$ & $\begin{array}{l}\text { Tour and } \\
\text { Travel }\end{array}$ & $\begin{array}{l}\text { Pokdarwis } \\
\text { Desa Celuk }\end{array}$ \\
\hline Desa Celuk & $\begin{array}{l}\text { The tukad } \\
\text { Rafting }\end{array}$ & $\begin{array}{l}\text { Celuk Design } \\
\text { Center }\end{array}$ \\
\hline BUMDes & & $\begin{array}{l}\text { Koperasi } \\
\text { pengrajin } \\
\text { perak celuk }\end{array}$ \\
\hline
\end{tabular}

Sumber: Hasil Penelitian, 2019

Pelayanan tambahan yang disediakan oleh stakeholder pariwisata di Desa Celuk sudah cukup baik. Pembangunan fisik di Desa Celuk sudah terlaksana dengan adanya jalan raya, bangunan bangunan pemerintah yang memadai, terpenuhi pasokan air, jaringan listrik dan bangunan fisik lainnya. Kelembagaan pariwisata sudah berjalan dengan baik terbukti adanya sinergitas antara masyarakat, pelaku pariwisata, pokdarwis dan pemerintah Desa Celuk. Selain pokdarwis, Desa Celuk memiliki Celuk Design Center (CDC) dan Koperasi Pengrajin Perak Celuk yang memiliki tugas dan tanggung jawab dalam pengembangan kerajinan perak di Desa Celuk yang terdiri dari lebih kurang 438 pengrajin perak. Celuk Design Center bertanggung jawab melindungi desain kerajinan perak yang dianggap hal penting, mereka juga mengajari generasi muda teknik pembuatan kerajinan perak yang modern dan berinovasi dengan mode.

Koperasi Pengrajin Perak Celuk terdiri dari masyarakat home industry, koperasi ini digunakan masyarakat untuk membeli bahan baku dan sarana pameran kerajinan melalui organisasi secara umum. Dinas Pariwisata Gianyar mengawasi dan menetapkan Desa Celuk sebagai desa wisata dengan kriteria kriteria yang dimilikinya. BUMDes membantu mengelola salah satu atraksi wisata yang akan di bangun. The Tukad Rafting diharapkan mampu dan ingin membantu mengembangkan sungai Wos yang akan dibuatkan sport activity dan tubing. 
Tabel 2 Crossing produk wisata dan A4

\begin{tabular}{|c|c|c|c|c|}
\hline $\begin{array}{l}\text { Produk } \\
\text { Wisata }\end{array}$ & Attraction & Access & Amenities & Ancillary \\
\hline $\begin{array}{l}\text { Kerajinan } \\
\text { perak } \\
\text { Celuk }\end{array}$ & $\begin{array}{l}\text { 1. Melihat secara } \\
\text { langsung } \\
\text { bagaimana } \\
\text { pengolahan } \\
\text { kerajinan perak. } \\
\text { 2. Wisatawan dapat } \\
\text { belajar bagaimana } \\
\text { cara membuat } \\
\text { kerajinan perak. }\end{array}$ & $\begin{array}{lr}\text { Sepanjang } & \text { Jalan } \\
\text { Raya } & \text { Celuk } \\
\text { wisatawan dapat } \\
\text { melihat banyaknya } \\
\text { artshop rang } \\
\text { menjual kerajinan } \\
\text { Perak Celuk. }\end{array}$ & $\begin{array}{l}\text { Fasilitas yang disediakan } \\
\text { dimasing masing artshop } \\
\text { yaitu etelase tempat } \\
\text { melihat hasil kerajinan } \\
\text { perak, tempat demo } \\
\text { membuat perak, gazebo } \\
\text { tempat beristirahat, } \\
\text { tempat parkir disetiap } \\
\text { artshop. }\end{array}$ & $\begin{array}{l}\text { 1. Celuk Design } \\
\text { Center } \\
\text { 2. Koperasi } \\
\text { Pengrajin Perak } \\
\text { Celuk } \\
\text { 3. Desa Celuk }\end{array}$ \\
\hline $\begin{array}{l}\text { Museum } \\
\text { Perak } \\
\text { Celuk }\end{array}$ & $\begin{array}{l}\text { Mendemostrasi } \\
\text { kan dan } \\
\text { memperlihatkan } \\
\text { bagaimana sejarah dan } \\
\text { perkembangan } \\
\text { kerajinan perak di Desa } \\
\text { Celuk. } \\
\text { Galeri - galeri yang } \\
\text { memperlihatkan desain } \\
\text { kerajinan perak Celuk } \\
\text { dari waktu ke waktu. }\end{array}$ & $\begin{array}{l}\text { Masih dalam tahap } \\
\text { perencanaan } \\
\text { pembangunan, } \\
\text { rencananya akan } \\
\text { dibangun didekat } \\
\text { LPD. }\end{array}$ & $\begin{array}{l}\text { Masih dalam tahap } \\
\text { rencana pembangunan. }\end{array}$ & $\begin{array}{l}\text { Bentuk pengelolaan } \\
\text { museum belum di } \\
\text { rencanakan oleh } \\
\text { pemerintah terkait. }\end{array}$ \\
\hline Swing & $\begin{array}{l}\text { Aktifitas ayunan } \\
\text { dengan latar belakang } \\
\text { tebing dan sungai Wos. }\end{array}$ & $\begin{array}{l}\text { Dimana persisnya } \\
\text { akan di buat swing } \\
\text { masih harus dikaji } \\
\text { terlebih dahulu. }\end{array}$ & $\begin{array}{l}\text { Masih dalam tahap } \\
\text { rencana pembuatan } \\
\text { aktifitas swing. }\end{array}$ & \begin{tabular}{lr}
\multicolumn{2}{l}{ Rencananya akan } \\
di kelola bersama \\
oleh Desa Celuk, \\
pokdarwis \\
masyarakat.
\end{tabular} \\
\hline $\begin{array}{l}\text { Jalur } \\
\text { trekking }\end{array}$ & $\begin{array}{l}\text { Perjalanan menyusuri } \\
\text { areal persawahan dan } \\
\text { sungai Wos }\end{array}$ & $\begin{array}{l}\text { Akses menuju areal } \\
\text { persawahan sudah } \\
\text { baik namun untuk } \\
\text { akses menuju } \\
\text { sungai masih perlu } \\
\text { penataan. }\end{array}$ & $\begin{array}{l}\text { Jalur trekking yang masih } \\
\text { dalam tahap pembuatan } \\
\text { dan penataan. }\end{array}$ & $\begin{array}{l}\text { Rencananya akan } \\
\text { dikelola bersama } \\
\text { oleh masyarakat, } \\
\text { Desa Celuk dan } \\
\text { pokdarwis }\end{array}$ \\
\hline Tubing & \begin{tabular}{lrr} 
Aktivitas & \multicolumn{2}{c}{ menyusuri } \\
medan sungai & Wos \\
dengan ban karet & sepanjang hampir $2 \mathrm{~km}$.
\end{tabular} & $\begin{array}{lr}\text { Jalan turun menuju } \\
\text { sungai ada dua, } \\
\text { pertama } & \text { dari } \\
\text { jembatan } & \text { zaman } \\
\text { Belanda dan } & \text { di } \\
\text { dekat LPD. } & \end{array}$ & \begin{tabular}{ll} 
Tahap & pembenahan, \\
penataan & \multicolumn{2}{c}{ walaupun } \\
masih & menentukan \\
penataan & cocok di \\
bantaran & sungai
\end{tabular} & $\begin{array}{l}\text { Rencananya akan } \\
\text { dikelola bersama } \\
\text { oleh Desa Celuk, } \\
\text { Masyarakat, } \\
\text { pokdarwis, The } \\
\text { Tukad Rafting, } \\
\text { Investor }\end{array}$ \\
\hline $\begin{array}{l}\text { Jembatan } \\
\text { zaman } \\
\text { Belanda }\end{array}$ & Wisata foto & $\begin{array}{l}\text { Berada di dekat } \\
\text { berbatasan } \\
\text { Sukawati dan Celuk. }\end{array}$ & $\begin{array}{l}\text { Jembatan, jalan } \\
\text { masih dalam } \\
\text { renovasi }\end{array}$ & $\begin{array}{l}\text { Rencananya akan } \\
\text { dikelola bersama } \\
\text { oleh Desa Celuk, } \\
\text { Masyarakat, } \\
\text { Pokdarwis } \\
\end{array}$ \\
\hline
\end{tabular}

Sumber : Hasil Penelitian, 2019

\section{Strategi diversifikasi produk wisata untuk menarik minat wisatawan}

Data yang diperoleh dari penelitian ini dianalisa dengan teknik SWOT. Penentuan strategi diversifikasi dilakukan dengan membuat matriks SWOT dan disusun berdasarkan internal dan eksternal yang dimiliki Desa Celuk. Kemudian ditentukan strategi prioritas diversifikasi produk wisata.

\section{a. Kekuatan (Strength)}

Kekuatan yang dimiliki oleh Desa Celuk yaitu: 1) Desa Celuk memiliki potensi budaya dan potensi alam yang dapat dikembangkan menjadi daya tarik wisata yang diminati wisatawan. 2) Desa Celuk sudah memiliki masterplan pengembangan potensi wisata yang dimiliki berupa pengembangan sungai Wos. 3) Desa Celuk telah membuat IG (Indikasi Geografis) untuk kerajinan perak sehingga wisatawan dapat 
membedakan hasil kerajinan perak Desa Celuk dengan daerah lain. 4) Dukungan masyarakat terhadap perkembangan Desa Celuk, dan di tetapkannya Desa Celuk sebagai salah satu desa wisata yang ada di Kabupaten Gianyar. 5) Desa Celuk memiliki Stakeholder yang berkaitan dengan pariwisata dan mampu menjaga keberlangsungan pariwisata dan lingkungan di Desa Celuk. 6) Desa Celuk memiliki areal persawahan yang sangat luas yang dapat dimanfaatkan sebagai pertanian organik disamping sebagai potensi wisata.

b. Kelemahan (Weakness)

Kelemahan yang dimiliki dalam pengembangan Desa Celuk sebagai salah satu desa wisata di Kabupaten Gianyar: 1) Masih banyak sampah di sekitar sungai Wos yang dapat menyebabkan air tercemar dan merusak pemandangan. 2) Belum ada penataan di tempat yang akan dijadikan jalur trekking. 3) Pengelolaan yang masih baru terbentuk sehingga kesadaran generasi muda masih belum turut aktif dalam melakukan pengembangan. 4) Biaya yang akan digunakan dalam pengembangan Desa Celuk lumayan besar. 5) Belum disosialisasikan kepada masyarakat mengenai IG yang sudah didaftarkan. 6) Promosi secara berkala belum optimal.

\section{c. Peluang (Opportunity)}

Peluang yang dapat dimanfaatkan Desa Celuk dalam Pengembangan pariwisata: 1) Desa Celuk merupakan jalur wisata Batubulan - Sukawati - Ubud - Kintamani. 2) Sejumlah calon wisatawan telah mengetahui IG yang didaftarkan Desa Celuk. 3) Banyak Travel Agent memasukkan Desa Celuk sebagai salah satu destinasi tujuan didalam tour. 4) Ada beberapa investor yang ingin ikut ambil andil dalam pengembangan Desa Celuk di beberapa bidang usaha. 5) Masyarakat dapat menargetkan wisatawan yang menonton kesenian Barong Dance untuk melihat dan membeli hasil kerajinan perak.

d. Ancaman (Threat)

Hambatan yang akan mengganggu Desa Celuk dalam pengembangan pariwisata: 1) Desain perak Celuk yang sering ditiru dan dipalsukan orang yang tidak bertanggung jawab. 2) Kurangnya tenaga ahli yang dapat mendampingi Desa Celuk melakukan pengembangan dalam bidang pariwisata. 3) Perubahan segmentasi pasar dari kerajinan perak Celuk dan penurunan jumlah kunjungan wisatawan. 4) Bencana alam seperti banjir yang menyebabkan air sungai meluap.

Berdasarkan data yang telah didapatkan maka diperoleh strategi sebagai berikut:

a. Strategi S-O

Strategi yang dibuat bersadarkan kekuatan yang dimiliki Desa Celuk untuk memanfaatkan peluang dalam pengembangan nya: 1) Potensi alam dijadikan andalan untuk menarik wisatawan minat khusus pelestarian lingkungan yang menginginkan sarana yang lengkap dan sesuai dengan kondisi lingkungan di Desa Celuk. 2) Sinergi antara masyarakat dan investor dalam mengembangkan potensi wisata yang dimiliki Desa Celuk sehingga dapat terwujudnya masterplan pengembangan Sungai Wos sebagai tempat kegiatan sport activity. 3) Adanya kegiatan masyarakat dibidang pertanian organik dapat dimanfaatkan sebagai wisata edukasi yang melibatkan masyarakat secara langsung sehingga dapat dijadikan salah satu atraksi wisata di Desa Celuk. 4) Mengadakan pelatihan dan melakukan perekrutan masyarakat lokal sebagai pengelola pariwisata di Desa Celuk serta memberikan masyarakat pemahaman mengenai desa wisata dan potensi yang dimiliki oleh Desa Celuk dalam bidang pariwisata. 5) Mengoptimalkan stakeholder pariwisata untuk memperkenalkan IG kepada wisatawan dan dicantumkan dideskripsi website travel agent agar seluruh calon wisatawan mengetahuinya.

b. Strategi $\mathrm{W}-\mathrm{O}$

Strategi yang dibuat berdasarkan memanfaatkan peluang yang dimiliki untuk meminimalisir kelemahan dalam pengembangan pariwisata di Desa Celuk: 1) Membangun fasilitas fasilitas dan melakukan penataan di Sungai Wos dan menjalankan kerjasama yang baik ke berbagai sektor untuk keberlangsungan pariwisata. 2) Meningkatkan pelatihan dan pemahaman generasi muda untuk melihat peluang usaha dibidang kerajinan perak dengan menyasar wisatawan - wisatawan yang melakukan wisata melewati Desa Celuk. 3) Meningkatkan kesadaran masyarakat untuk membuang sampah pada tempatnya dengan disediakan tempat sampah umum sehingga sungai terlihat bersih. 4) Bersinergi dengan investor untuk mengakomodasikan biaya pengembangan Desa Celuk dan melakukan promosi secara optimal.

c. Strategi S-T

Strategi yang menggunakan kekuatan untuk menghadapi ancaman dalam pengembangan pariwisata di Desa Celuk: 1) Membuat paket wisata alam yang bersifat lebih dekat dengan alam dan dikombinasikan dengan kegiatan yang menyenangkan lainnya. Dengan pengembangan paket wisata di Desa Celuk, meskipun jumlah kunjungan wisatawan lebih sedikit namun pendapatan lebih besar. 2) Melakukan kajian terhadap potensi alam dengan bekerjasama dengan tenaga ahli yang mengetahui siklus sungai dan persawahan sehingga dapat melakukan tindakan sebelum terjadi bencana. 3) Memperkenalkan IG yang sudah di daftarkan sehingga wisatawan dapat membedakan kerajinan perak Celuk yang asli sehingga dapat mengembalikan kepercayaan wisatawan terhadap kerajinan perak Celuk.

d. Strategi W-T 
Vol. 8 No 1, 2020

Strategi yang berusaha meminimalkan kelemahan yang ada untuk menghindari ancaman dalam pengembangan pariwisata di Desa Celuk: 1) Melakukan sosialisasi kepada masyarakat Mengenai IG dan manfaatnya sehingga masyarakat tidak perlu merasa khawatir dengan kerajinan perak tiruan yang lebih murah dan banyak dijual dipasaran. 2) Menciptakan sistem pemeliharaan potensi dengan baik dan terstruktur sehingga bisa menjaga kelestarian dan keberlanjutan pariwisata di Desa Celuk. 3) Mengikut sertakan masyarakat dalam melaksanakan kegiatan pariwisata sehingga masyarakat dapat memahami dan ikut serta dalam mengambil keputusan sehingga masyarakat merasa dilibatkan dan ikut serta berperan aktif dalam pengembangan pariwisata di Desa Celuk.

4. Strategi Prioritas Divervisifikasi Produk Wisata Di Desa Celuk

Penentuan strategi prioritas berdasarkan keadaan dilapangan maka dirumuskan :

\section{Jangka Pendek (1 - 5 tahun) Jangka Menengah (5 - 10 tahun) \\ Jangka Panjang (10 - 20 tahun)}

Potensi alam dijadikan andalan untuk menarik wisatawan minat khusus pelestarian lingkungan yang menginginkan sarana lengkap sesuai dengan kondisi lingkungan di Desa Celuk.

Adanya kegiatan masyarakat dibidang pertanian organik dapat dimanfaatkan sebagai wisata edukasi yang melibatkan masyarakat secara langsung sehingga dapat dijadikan salah satu atraksi wisata di Desa Celuk.

Meningkatkan kesadaran masyarakat untuk membuang sampah pada tempatnya dengan disediakan tempat sampah umum sehingga sungai tetap terlihat bersih.

\begin{tabular}{|l}
\hline Melakukan kajian terhadap \\
potensi alam dengan \\
bekerjasama dengan tenaga ahli \\
yang mengetahui siklus sungai \\
dan persawahan sehingga dapat \\
melakukan tindakan sebelum \\
terjadinya bencana alam. \\
\hline
\end{tabular}

Melakukan sosialisasi kepada masyarakat mengenai IG dan manfaatnya sehingga masyarakat tidak perlu merasa khawatir dengan kerajinan perak tiruan yang lebih murah dan banyak dijual dipasaran.
Mengoptimalkan stakeholder pariwisata untuk memperkenalkan IG (Indikasi Geografis) kepada wisatawan dan dicantumkan di deskripsi website travel agent agar seluruh calon wisatawan mengetahuinya.

Membangun fasilitas fasilitas dan melakukan penataan di Sungai Wos dengan menjalankan kerjasama yang baik ke berbagai sektor untuk keberlangsungan pariwisata di Desa Celuk.

Membuat paket wisata alam yang bersifat lebih dekat dengan alam dan dikombinasikan dengan kegiatan yang menyenangkan. Dengan mengembangkan paket wisata, meskipun jumlah kunjungan wisatawan lebih sedikit namun pendapatannya akan lebih besar.

Memperkenalkan IG yang sudah didaftarkan sehingga wisatawan dapat membedakan kerajinan Perak Celuk yang asli agar wisatawan dapat mengembalikan kepercayaan wisatawan terhadap kerajinan Perak Celuk. Bersinergi dengan investor untuk Mengikutsertakan masyarakat mengakomodasikan biaya dalam melaksanakan kegiatan pengembangan Desa Celuk dan pariwisata sehingga masyarakat melakukan promosi secara optimal.
Bersinergi antara masyarakat dan investor dalam mengembangkan potensi wisata yang dimiliki Desa Celuk sehingga terwujudnya masterplan pengembangan Sungai Wos sebagai tempat kegiatan sport activity.

Mengadakan pelatihan dan melakukan perekrutan masyarakat lokal sebagai pengelola pariwisata di Desa Celuk serta memberikan masyarakat pemahaman mengenai desa wisata dan potensi yang dimiliki oleh Desa Celuk dalam bidang pariwisata.

Meningkatkan pelatihan dan pemahaman generasi muda untuk melihat peluang usaha dibidang kerajinan perak dengan menyasar wisatawan yang melakukan wisata melewati Desa Celuk

Menciptakan sistem pemeliharaan potensi dengan baik dan terstruktur sehingga bisa menjaga kelestarian dan keberlanjutan pariwisata di Desa Celuk. dapat memahami dan ikut serta dalam mengambil keputusan agar masyarakat merasa dilibatkan dan ikut aktif berperan serta dalam pengembangan pariwisata di Desa Celuk

\section{Sumber : Hasil penelitian, 2019}

\section{PENUTUP}

Berdasarkan hasil penelitian yang telah dilakukan di Desa Celuk mengenai strategi diversifikasi produk wisata untuk menarik minat kunjungan wisatawan maka diperoleh kesimpulan: Desa Celuk memiliki banyak potensi yang dapat dikembangkan menjadi destinasi wisata. Potensi yang dimiliki Desa Celuk seperti kerajinan perak, 
persawahan, sungai, dan jembatan peninggalan Belanda saat ini dalam tahap perkembangan dan perencanaan. Fasilitas penunjang pariwisata di Desa Celuk dapat digunakan sebaik mungkin, para stakeholder pariwisata ikut turun langsung dalam pengembangan pariwisata di Desa Celuk.

Strategi diversifikasi produk wisata di Desa Celuk ditekankan pada pelibatan masyarakat dikarenakan masyarakat yang akan menjadi objek sekaligus subjek dari pariwisata. Melakukan sosialisasi kepada masyarakat desa mengenai pariwisata yang sedang dikembangkan agar masyarakat dapat turut serta dalam melakukan pengembangan dan mendukung terlaksananya kegiatan pariwisata di Desa Celuk.

Adapun saran yang dapat diberikan berdasarkan penelitian ini adalah:

1. Pemerintah agar dapat membantu dalam pemberian dana dan pemberian pelatihan terkait pawisata agar masyarakat Desa Celuk dapat merasakan langsung dampak positif dari pariwisata sehingga pemerintah dapat melihat bagaimana pengembangan yang signifikan dan pemasukan dari sektor pariwisata di Desa Celuk.

2. Stakeholder agar mengikutkan masyarakat dalam pengambilan keputusan terkait pariwisata karena masyarakat akan terlibat langsung dalam pelaksanaan kegiatan pariwasata.

3. Masyarakat agar lebih sering mengupdate kegiatan pariwisata atau tren pariwisata yang ada di desa. Masyarakat yang berpartisipasi memberikat manfaat positif terhadap keberlanjutan pariwisata di Desa Celuk.

Strategi diversifikasi produk wisata di Desa Celuk dititik beratkan pada pelibatan masyarakat agar kegiatan wisata berjalan dengan baik dan memiliki dampak yang positif. Pelibatan masyarakat sebagai pengambilan keputusan yang sesuai berdasarkan keadaan dilapangan karena masyarakat paham inovasi diinginkan wisatawan yang berinteraksi langsung dengan mereka. Sehingga pariwisata dapat berkelanjutan.

\section{DAFTAR PUSTAKA.}

Anom, I Putu dan Mahagangga, I Gusti Agung Oka. 2020. Handbook Ilmu Pariwisata Karakter dan Prospek. Jakarta: Prenada Media.

Badan Pusat Statistik Kabupaten Gianyar. 2018. Kecamatan Sukawati Dalam Angka 2018. Badan Pusat Statistik Kabupaten Gianyar. Gianyar

Bungin, Burhan. (2007). Penelitian Kualitatif Komunikasi, Ekonomi, Kebijakan Publik dan Ilmu Sosial Lainnya. Jakarta : Prenada Media Group
Darmaja, I. Made; Suwena, I. Ketut; Sendra, I. Made. (2001). Model Kemasan Paket Wisata Batur Global Geopark Menuju Pariwisata Berkelanjutan Di Kintamani. Jurnal Ipta, 4.1: 20-25

Hariyana, I. K., \& Mahaganggaa, I. G. A. O. (2015). Persepsi Masyarakat Terhadap Pengembangan Kawasan Goa Peteng Sebagai Daya Tarik Wisata Di Desa Jimbaran Kuta Selatan Kabupaten Badung. Jurnal Destinasi Pariwisata ISSN, 2338, 8811.

Lustinayanti, Wayan Emi; Kurniawati, Natalia Sri Endah. (2017). Pengaruh Waiting Time Terhadap Kepuasan, Loyalitas Dan Wom Pada Industri Perak di Desa Celuk Sukawati Gianyar Bali.Jurnal Ekonomi Dan Pariwisata

Mahagangga, I Gusti Agung Oka. 2016. Percepatan Pengembangan Pariwisata Kabupaten Blitar Provinsi Jawa Timur. Makalah Presentasi Workshop Percepatan Pengembangan Pariwisata Blitar. Denpasar. DOI: 10.13140/RG.2.2.15793.81769

Moleong, Lexi. (2012). Metodologi Penelitian Kualitatif. Bandung:PT. Renaja Rosdakarya

Naibaho, Evenin R. (2011). Diversifikasi Produk Wisata Di Pulau Samosir, Kabupaten Samosir, Provinsi Sumatera Utara. Skripsi Dipublikasikan. Institut Pertanian Bogor, Bogor

Narottama, N. (2016, May). The Implementation of Cultural Based-Holistic Management Concept to Minimized The Negative Impacts of Tourism Case Study: Coastal Area of Sanur, Bali. In Asia Tourism Forum 2016-the 12th Biennial Conference of Hospitality and Tourism Industry in Asia. Atlantis Press.

Nyoman, I.; Wiyasa, Ngidep. (2008). Kerajinan Perak Di Desa Celuk Kajian Aspek Disain Dan Inovasinya. Artikel Bulan Januari, Institut Seni Indonesia Denpasar, 2.1: 1-1.

Parimin, Parimin. (2007). Strategi Diversifikasi Produk Wisata Untuk Menarik Minat Kunjungan Wisatawan di Sentra Ikan Bulak (Sib) Kenjeran Surabaya.Tourism, Hospitality and Culinary Journal. 3.1: 45-55.2018 Persada

Pitana, I Gde. 2002. Pariwisata Wahana Kelestarian Kebudayaan dan Dinamika Masyarakat Bali. Denpasar: Universitas Udayana.

Rangkuti, Freddy. (2003). Analisis SWOT Teknik Membedah Kasus Bisnis. Jakarta: Penerbit PT Gramedia Pustaka Utama.

Sugiyono. (2010). Metode Penelitian Kuantitatif, Kualitatif dan $R \& D$. Bandung : $\quad$ Alfabeta.

Sukmaratri, Myrna; Damayanti, Maya. (2016). Diversifikasi Produk Wisata Sebagai Strategi Pengembangan Daya Saing Wisata Kota Batu.Jurnal Pembangunan Wilayah \& Kota, 12.3: 325-335 
Vol. 8 No 1, 2020

Undang Undang Republik Indonesia Nomor 10 tahun 2009 Tentang Kepariwisataan

Wulandari, I. G. A. A., \& Parameswara, A. A. G. A. (2020). Problematika UMKM Berbasis Budaya Lokal di Bali (Studi Kasus Pemasaran Produk UMKM Berbasis Budaya Lokal di Pesta Kesenian Bali). Ekonomi dan Bisnis, 6(2), 101120.

Sumber internet:

BPNB Bali, 2018, Sejarah Kerajinan Perak Celuk di Gianyar dalam (https://kebudayaan.kemdikbud.go.id/bpnbba li/sejarah-kerajinan-perak-celuk-di-gianyar/.) di akses pada 24 april 2019 pukul 18.26

DetikNews, 2018, Warga Gianyar Ajukan 'Hak Paten' Kerajinan Perak Desa Celuk dalam (https://news.detik.com/berita/d4264203/w arga-gianyar-ajukan-hak-paten-kerajinanperak-desa-celuk) diakses pada 13 april 2019 pukul 19.20

NusaBali, 2017, Dulu jaya, Sekarang Berharap 'Rembesan' dalam (https://www.nusabali.com/berita/14818/du lu-jaya-sekarang-berharap-rembesan) diakses pada 11 april 2019 pukul 16.43 